\title{
Thermo-Mechanical Behavior of the Continuous Casting Bloom in the Heavy Reduction Process
}

\author{
CHENG JI, ${ }^{1}$ CHEN-HUI WU, ${ }^{1}$ and MIAO-YONG ZHU ${ }^{1,2}$ \\ 1.-School of Metallurgy, Northeastern University of China, No. 3-11, Wenhua Road, Heping \\ District, Shenyang 110819, Liaoning, China. 2.—e-mail: myzhu@mail.neu.edu.cn
}

\begin{abstract}
A two-stage sequential heavy reduction (HR) method, in which the reduction amount was increased both before and after the solidification end, is presented to simultaneously improve the homogeneity and compactness of the continuous casting bloom. With bearing steel GCr15 chosen as the specific research steel, a three-dimensional thermal-mechanical finite element model was developed to simulate and analyze the thermal and mechanical behaviors of the continuous casting bloom during the HR process. In order to ensure the accuracy of the simulation, the constitutive model parameters were derived from the experimental results. The predicted temperature distribution and shell thickness were verified using a thermal infrared camera and nail shooting results, respectively. The real measured relationship between the HR pressure and amount were applied to verify the mechanical model. The explorative application results showed that the quality of the bloom center and compactness of rolled bars have both been significantly improved after the HR was applied.
\end{abstract}

\section{INTRODUCTION}

Soft reduction (SR) technology is an effective method to reduce the slab and bloom centerline segregation as well as porosity in the continuous casting process. $^{1,2} \mathrm{SR}$ is usually implemented in the mushy zone to compensate for liquid core shrinkage and to prevent the solute-enriched liquid flowing toward the center of the strand. However, it is difficult to conquer the solidification shrinkage completely after the SR zone. Furthermore, in the continuous casting process of blooms or slabs with larger section sizes, the regular SR amount is not enough to conquer the dissipation of the reduction energy caused by the thicker shell deformation, and the center quality could not be efficiently improved. On the other hand, the temperature difference between the strand surface and center is approximately $400^{\circ} \mathrm{C}$ at the solidification end, indicating that the compactness of the strand center could be effectively improved by means of increasing the reduction amount at and after the solidification end due to the temperature gradient. According to the above-mentioned reasons, heavy reduction (HR) technology, which imposes a larger reduction rate/ amount at and after the solidification end of the strand, was developed for healing the solidification shrinkage cavity and for improving the center density.

In the early 1990s, Kawasaki Steel Corp. proposed and applied continuous forging technology in the bloom continuous casting process to control the porosity and segregation of the center. ${ }^{3,4}$ In this method, the solidifying shells were pressed into contact with each other by forging them down with a pair of anvils installed at the solidification end, and the center segregation and porosity were successfully improved. Increasing numbers of researchers have realized that the quality of the center of the slab and bloom could be significantly improved by means of increasing the reduction amount/rate at the solidification end. Nippon Steel presented NS Bloom Large Reduction Technology, ${ }^{5}$ which applied a large reduction amount after the complete solidification end of the continuous casting bloom by a pair of convex-shaped rolls. With these, the reduction energy could be concentrated onto the bloom center, and the center porosity could be efficiently reduced. Sumitomo Metal Industries also developed a HR method called porosity control of the casting slab (PCCS). ${ }^{6,7}$ With the PCCS technology, the center porosity of the very thick continuous casting 
slab could be significantly decreased by the large roll reduction just before the end of solidification. $\mathrm{Yu}$ et al. $^{8}$ verified the effect of the temperature gradient of the rolling process on improving the center porosity of the ultra-heavy plate by means of a physical rolling experiment and numerical simulation, and this process could be regarded as a type of HR method if the reduction positions were located before the torch cutoff of the caster. In the above-mentioned methods, the HR position was usually fixed on the strand, and the internal quality of the slab or bloom was hardly improved under any circumstances due to the unfixed solidification end, especially when the casting speed or the casting steel grade was changed. Therefore, POSCO provided a type of flexible HR method, which was executed by several segments at the strand solidification end, and the maximum reduction rate was $30 \mathrm{~mm} / \mathrm{min} .{ }^{9}$ Zhao et al. ${ }^{10,11}$ proposed a new HR approach, called the heavy reduction process to improve segregation and porosity (HRPISP), and they simulated the deformation and dynamic recrystallization (DRX) behavior of the HR process of the extra-thick slab by using the THERCAST.

It can be inferred that powerful mechanical, hydraulic, and motor-driven equipment is usually required to implement $\mathrm{HR}$, and the corresponding investment cost of upgrading the caster is much higher. In the present work, a two-stage sequential HR method was designed while still making full use of the original withdrawal and straightening units' capacities. In the first stage, the reduction amount was greatly enhanced before the solidification end to improve the homogeneity of the bloom, and in the second stage, the bloom was greatly compressed at and after solidification by the following units with their maximum reduction capability to improve the compactness of the bloom. In this method, the upgrade of equipment is not necessary, and the reduction parameters could be adjusted flexibly according to the specific casting conditions. With the specific parameters of a bloom continuous casting machine, a threedimensional thermo-mechanical coupled finite element model was built to describe the effect of the $\mathrm{HR}$ on the thermal and mechanical behaviors of the bearing steel GCr15 bloom. In order to improve the accuracy of the simulation results, the constitutive model for the GCr15 bloom was derived from the experimental results. The mechanical model was validated by the real measured relationship between the reduction pressure and the amount of withdrawal and straightening units, and the predicted temperature distribution as well as shell thickness were verified by the results of a thermal infrared camera and nail shooting, respectively. A typical HR case of the steady-state casting process was simulated, and the temperature distribution, shell thickness, reduction amount and equivalent strain at the bloom surface and inside were analyzed and compared. Finally, the results of explorative industrial application were presented.

\section{MATHEMATICAL MODELING}

The deformation behavior of the strand shell has a significant effect on the fluid flow and macrosegregation in the mushy zone, which had been proven by the pioneering work of Miyazawa and Schwerdtfeger ${ }^{12}$ and the work of Kajitani et al. ${ }^{13}$ Wu et al. ${ }^{14}$ developed a two-phase columnar solidification model to describe the effect of shell deformation on the macro-segregation behavior, and the mechanism of SR was derived according to the simulation results. However, the shell deformation behavior of the HR process is different from that of the SR process due to its dramatically increased reduction amount, so in this work, a 3-D thermalmechanical coupled FE model was developed to describe the shell deformation behavior during the sequential reduction process.

In the present work, a 4-strand arc bloom continuous casting machine was chosen as the specific research objective as shown in Fig. 1. The bloom section is $380 \mathrm{~mm} \times 490 \mathrm{~mm}$ at room temperature, and the reduction is executed by withdrawal and straightening units located in the air cooling zone. The caster was originally designed by CONCAST, and the maximum cylinder pressure of the withdrawal and straightening units is $1900 \mathrm{kN}$. A type of bearing steel, GCr15, was chosen as the specific steel grade used in this research, and the main composition was 1.00 wt.\% C, 0.25 wt. $\% \mathrm{Si}, 0.30$ wt.\% Mn, 0.01 wt. $\%$ P, 0.01 wt. $\%$ S, and 1.45 wt. $\%$ Cr.

Due to the symmetry of the bloom in the width direction, one-half of the bloom, with dimensions of $1200 \mathrm{~mm} \times 245 \mathrm{~mm} \times 380 \mathrm{~mm}$, was chosen as the research object as shown in Fig. 2. Based on some simplified assumptions, ${ }^{15,16}$ a $3-\mathrm{D}$ thermal-

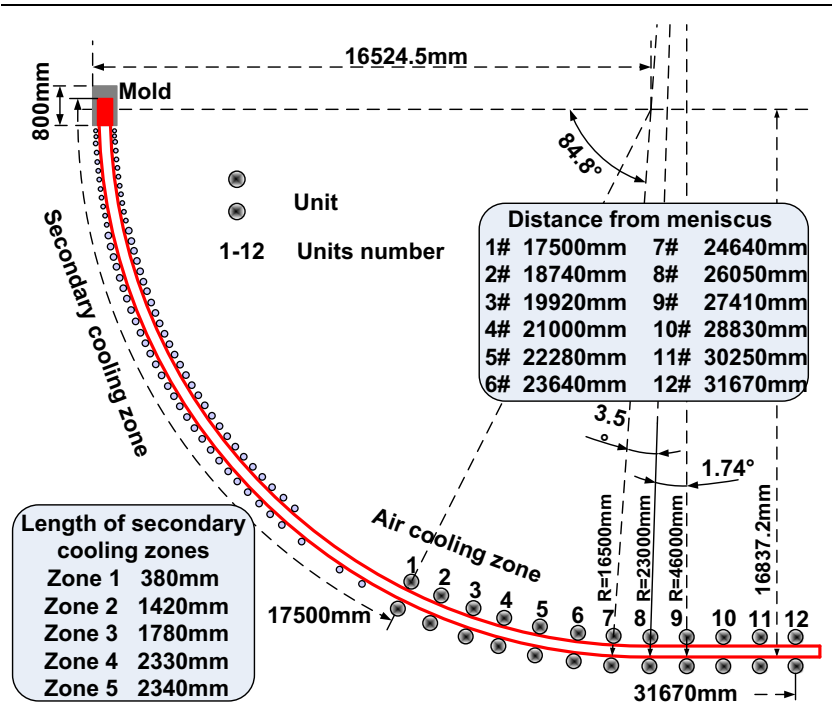

Fig. 1. The schematic of the bloom continuous casting machine. 


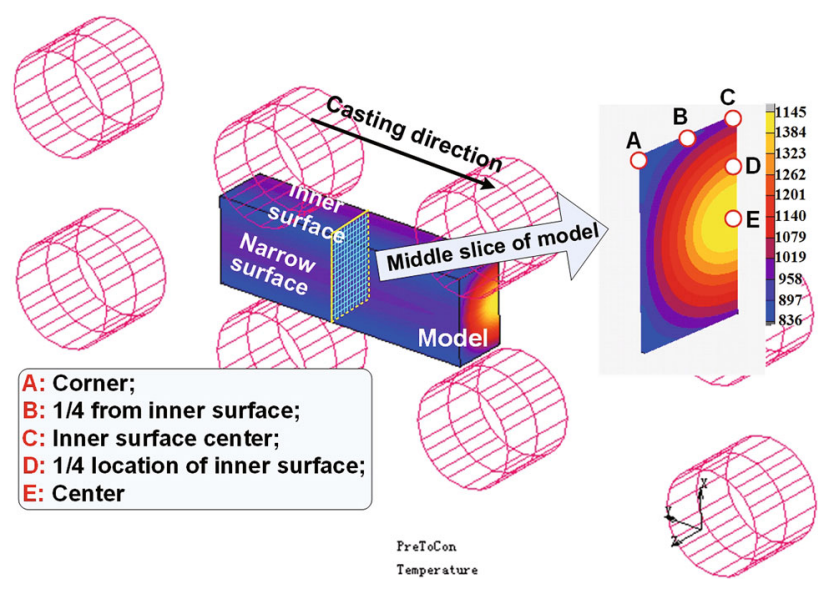

Fig. 2. 3-D thermal-mechanical coupled FE model and the locations of typical points in the model.

mechanical coupled FE model was developed using the commercial software Msc.Marc. Hexahedral finite elements were used to mesh the computation domain, and the thermal and mechanical analyses were carried out by using the sequential coupling method when the bloom goes through the strand from the meniscus to the caster end with a stable casting speed of $0.45 \mathrm{~m} / \mathrm{min}$. The heat flux and displacement at the symmetrical face of the model are assumed to be zero. The HR was executed by withdrawal and straightening units in the air cooling zone. In order to improve the calculation efficiency of the coupled model, only heat transfer was calculated before the bloom arrived at the first unit. The thermal and mechanical behavior of the typical points at the middle slice of the model were investigated and compared during the HR process. The locations of the typical points are shown and described in Fig. 2.

\section{Heat Transfer Model}

A 3-D transient heat conduction equation was employed to describe the heat transfer behavior as follows:

$$
\begin{aligned}
\rho(T) c(T) \frac{\partial T}{\partial t}= & \frac{\partial}{\partial x}\left(\lambda(T) \frac{\partial T}{\partial x}\right)+\frac{\partial}{\partial y}\left(\lambda(T) \frac{\partial T}{\partial y}\right) \\
& +\frac{\partial}{\partial z}\left(\lambda(T) \frac{\partial T}{\partial z}\right) .
\end{aligned}
$$

where $T$ and $t$ are the temperature in ${ }^{\circ} \mathrm{C}$ and calculation time in s, respectively. $\rho(T), c(T)$, and $\lambda(T)$ are the density in $\mathrm{kg} / \mathrm{m}^{3}$, specific heat in $\mathrm{J} /$ $\left(\mathrm{kg}{ }^{\circ} \mathrm{C}\right)$, and heat conductivity in $\mathrm{W} /\left(\mathrm{m}{ }^{\circ} \mathrm{C}\right)$, respectively $x, y$ and $z$ are the width, thickness, and length of the bloom, respectively.

Based on the present authors' previous work, ${ }^{1} \mathrm{a}$ microsegregation model was established for acquiring the material properties of GCr15 in the temperature range between the solidus and liquidus temperatures. The thermal parameters, such as the conductivity, enthalpy, density, etc., were calculated by weighted averaging of the phase fraction with the specific calculation equations, which have been described in detail by $\mathrm{Li}$ and Thomas. ${ }^{17}$

The boundary condition of heat transfer has been described in the present authors' previous work. ${ }^{1}$ In the mold, the heat flux decreases from the surface center to the corner due to the shrinkage of the shell. In the secondary cooling zone, the equivalent convection coefficients of each of the cooling zones were calculated according to the measured water flux distribution of the nozzles. The heat transfer caused by the roll-bloom contact was also considered. Before the first withdrawal and straightening unit, the heat extraction of the roll-bloom contact was considered by the average equivalent heat transfer coefficient method due to the smaller contact length. As for the withdrawal and straightening units, due to the larger radius of the rolls and longer roll-bloom contact length, the simulation domain between two neighboring rolls was divided accurately by different heat extraction methods. The heat extraction between the rolls and bloom, qec, could be calculated as follows:

$$
q_{\mathrm{ec}}=h_{\mathrm{ec}}^{\mathrm{i}} \cdot\left(T_{\text {surf }}-T_{\text {roll }}^{\mathrm{i}}\right) .
$$

where $h_{\mathrm{ec}}^{\mathrm{i}}$ is the equivalent convection coefficient between the $i$ th roll and bloom in $\mathrm{w} /\left(\mathrm{m}^{2}{ }^{\circ} \mathrm{C}\right)$ and $T_{\text {roll }}^{\mathrm{i}}$ is the temperature of the $i$ th roll. The $h_{\mathrm{ec}}^{\mathrm{i}}$ is approximately $\quad 1.0 \mathrm{~kW} /\left(\mathrm{m}^{2}{ }^{\circ} \mathrm{C}\right)-1.25 \mathrm{~kW} /\left(\mathrm{m}^{2 \mathrm{c}}{ }^{\circ} \mathrm{C}\right)$ based on the previous work of Xia and Schiefermüller, ${ }^{18}$ and the Tiroll is approximately $150-300^{\circ} \mathrm{C}$ according to the measured results of a thermal infrared camera.

\section{Constitutive Model}

The bloom deformation was mainly caused by HR, and the thermal strain is not considered in this work. An Anand constitutive model was used to describe the relationship between the inelastic strain rate, temperature and flow stress of GCr15 steel at high temperature. ${ }^{19,20}$ In this model, there is no explicit yield surface, and the loading and unloading criteria are not needed. A single scalar variable (deformation resistance, $s$ ) is used to represent the isotropic resistance to inelastic strain. The constitutive equation is given as follows:

$$
\dot{\varepsilon}_{\mathrm{p}}=A \exp \left(-\frac{Q}{\mathrm{RT}}\right)\left[\sin h\left(\xi \frac{\sigma}{s}\right)\right]^{\frac{1}{\mathrm{~m}}}
$$

where the evolution equation for $s$ is expressed as:

$$
\frac{\mathrm{d} s}{\mathrm{~d} t}=\left[h_{0}\left|1-\frac{s}{s^{*}}\right|^{\mathrm{a}} \operatorname{sign}\left(1-\frac{s}{s^{*}}\right)\right] \dot{\varepsilon}_{\mathrm{p}} .
$$

with

$$
s^{*}=\tilde{s}\left[\frac{\dot{\varepsilon}_{\mathrm{p}}}{A} \exp \left(\frac{Q}{\mathrm{RT}}\right)\right]^{\mathrm{n}}
$$


where $\dot{\varepsilon}_{\mathrm{p}}$ is the inelastic strain rate in $\mathrm{s}^{-1} ; s^{*}$ is the deformation resistance saturation value in $\mathrm{MPa} ; s$ is the deformation resistance in $\mathrm{MPa}$; $Q$ is the activation energy of hot deformation of $350.10 \mathrm{~kJ} / \mathrm{mol} ; A$ is the pre-exponential factor of $5.55 \times 1013 \mathrm{~s}^{-1}$; $\xi$ is the multiplier of stress of $2.32 ; m$ is the strain rate sensitivity of stress of $0.331 ; h_{0}$ is the hardening/softening constant of $6025 \mathrm{MPa}$; $\tilde{s}$ is the deformation resistance saturation coefficient of $238.6 \mathrm{MPa} ; n$ is the strain rate sensitivity of saturation of $0.0046 ; a$ is the strain rate sensitivity of hardening/softening of 1.1 ; and $s_{0}$ is the initial value for deformation resistance of $64 \mathrm{MPa}$.

The parameters of the constitutive model were derived from the experimental results, which were mainly quoted from the previous work of Hua et al. ${ }^{21}$ and complemented by the present authors' experiments with temperatures of $750^{\circ} \mathrm{C}, 850^{\circ} \mathrm{C}$, $1200^{\circ} \mathrm{C}$ and $1250^{\circ} \mathrm{C}$. The mean relative error between the calculated and experimental flow stress curves is lower than $2.06 \%$, which indicates that the constitutive equation could accurately describe the mechanical behavior of GCr15 steel. The details of the constitutive model will be described and discussed in detail in future publications.

In the present work, the temperature-dependent elastic modulus was calculated as the following relationship based on the experimental data from Mizukami: $^{22}$ influence of the mushy zone on the strand deformation. Bellet et al. ${ }^{24,25}$ considered that the slab could be divided as liquid part and a solid part by a so-called coherency temperature. The liquid part is modeled using a viscoplastic law, and the solid part is described by an elastic-viscoplastic law. However, Bellet et al. ${ }^{24}$ also noted that the constitutive equation of the coherent solid phase in the mushy zone is contested by the lack of experimental data. On the other hand, many researchers have applied the ferrostatic pressure as the mechanical boundary condition on the inside surface of the shell instead of the liquid core. ${ }^{13,16,17,26,27}$ Due to lack of accurate mechanical properties in the mushy zone of the GCr15 bloom, the latter method was adopted in the present work, and the ferrostatic pressure was taken as a mechanical boundary condition at the isotherm of the liquid impenetrable temperature (LIT). ${ }^{27}$ The ferrostatic pressure is calculated by

$$
P=\rho_{1} g h^{\mathrm{i}} .
$$

where $P$ is the ferrostatic pressure in $\mathrm{Pa} ; \rho_{1}$ is the steel density at the liquidus temperature in $\mathrm{kg} / \mathrm{m}^{3} ; g$ is the gravity acceleration in $\mathrm{m} / \mathrm{s}^{2}$; and hi is the vertical height from the meniscus to the $i$ th unit in $m$.

The roll rotates around its axis at the casting speed, and the bloom was driven by the frictional force between the rolls and the bloom while the coefficient of friction is constant at $0.3{ }^{16}$ The unit

$$
E(T)=\left\{\begin{array}{cc}
968-2.33 T+1.9 \times 10^{-3} \times T^{2}-5.18 \times 10^{-7} T^{3} & 600^{\circ} \mathrm{C} \leq T \leq T_{\mathrm{S}} \\
\frac{\left(T-T_{\mathrm{s}}\right) E_{\mathrm{ZST}_{\mathrm{ST}}+\left(T_{\mathrm{ZST}}-T\right) E_{\mathrm{S}}}^{T_{\mathrm{ZST}}-T_{\mathrm{S}}}}{E_{\mathrm{ZST}}} & T_{\mathrm{S}}<T \leq T_{\mathrm{ZST}} \\
& T>T_{\mathrm{ZST}}
\end{array}\right.
$$

where $E(T)$ is the elastic modulus in GPa. $T_{\mathrm{s}}$ and $T_{\mathrm{ZST}}$ are the solidus and zero strength temperature in ${ }^{\circ} \mathrm{C}$, respectively. $E_{\mathrm{S}}$ is the elastic module when the temperature is equal to $T_{\mathrm{S}}$ in GPa. EZST is the elastic module when the temperature is equal to $T_{\mathrm{ZST}}$, and it is set as $0.01 \mathrm{GPa}$.

The temperature-dependent Poisson's ratio, $v(T)$, is calculated as follows: ${ }^{23}$

$$
v(T)=\left\{\begin{array}{cc}
8.23 \times 10^{-5} T+0.278 & 600^{\circ} \mathrm{C} \leq T \leq T_{\mathrm{S}} \\
\frac{\left(T-T_{\mathrm{s}}\right) v_{\mathrm{ZST} T}\left(T_{\mathrm{ZST}}-T\right) v_{\mathrm{S}}}{T_{\mathrm{ZST}}-T_{\mathrm{S}}} & T_{\mathrm{S}}<T \leq T_{\mathrm{ZST}} \\
v_{\mathrm{ZST}} & T>T_{\mathrm{ZST}}
\end{array}\right.
$$

where $v_{\mathrm{S}}$ is Poisson's ratio when the temperature is equal to $T_{\mathrm{S}}$. $v_{\mathrm{ZST}}$ is Poisson's ratio when the temperature is equal to $T_{\mathrm{ZST}}$. The $v_{\mathrm{ZST}}$ could not be equal to 0.5 due to the numerical difficulty for the solver, and it is set as 0.499 .

In the continuous casting process, the mushy zone deformed together with the solidified shell, and there are two typical approaches to take into account the rolls were considered as rigid bodies, and the node to segment contact algorithm was used to detect the contact between the rolls and bloom. ${ }^{17}$ The tolerance for the roll penetration was chosen to be $0.25 \mathrm{~mm}$, and a penalty constraint was applied to avoid excessive roll penetration.

\section{Parameters}

A typical case of the steady-state casting process was simulated, in which the GCr15 steel was cast at $0.45 \mathrm{~m} / \mathrm{min}$ with a casting temperature of $1497^{\circ} \mathrm{C}$. In order to investigate the thermal and mechanical behaviors of the GCr15 bloom during the sequential reduction process, the reduction amounts of the second to eighth units were all assumed to be $4 \mathrm{~mm}$ in this case, and the total reduction amount was $28 \mathrm{~mm}$.

\section{Model Validation}

The heat transfer behavior was verified by the measured surface temperature and shell thickness. The surface temperature was measured by a 


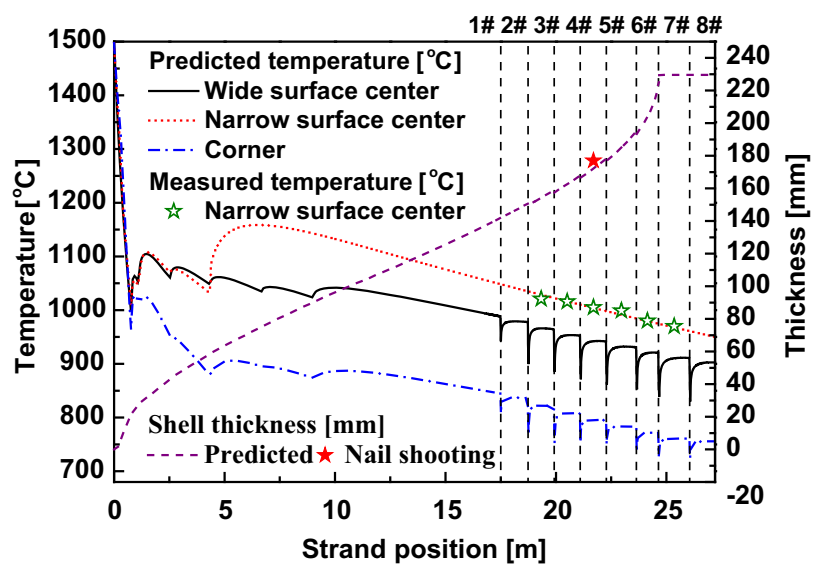

Fig. 3. Comparison between the predicted and measured surface temperature and shell thickness.

thermal infrared camera (A40, FLIR), and the shell thickness was measured by the nail shooting method. ${ }^{28}$ Figure 3 shows the comparison between the predicted and measured results. As shown in Fig. 3, the relative error between the predicted and measured temperatures on the bloom narrow surface center was $<0.91 \%$, while the relative error between the predicated shell thickness and nail shooting results was $<2.67 \%$.

Figure 4 shows the actual measured and predicted relationship between the reduction amount and pressure of each unit when the casting speed is $0.45 \mathrm{~m} / \mathrm{min}$. With increasing pressure, the reduction amount increased approximately as a quadratic function. The calculated pressure with a reduction amount of $4 \mathrm{~mm}$ was compared with the measured result to verify the accuracy of the mechanical model. As shown in Fig. 4, the relative errors between the calculated and measured pressures of each unit were all $<3.00 \%$ except those of the third and seventh units, which was possibly due to the original error of the magnetostrictive position sensors. The mean relative error of all of the units is $2.95 \%$.

\section{RESULTS AND DISCUSSION}

\section{Distribution of the Surface Temperature and Solidified Shell}

Figure 5 shows the temperature distribution of typical points on the inner surface during the HR process. Due to the contact between the bloom and rolls, the temperature dips under the roll-bloom contact areas were obvious. As for points $B$ and $C$, the temperature dips under each unit are both nearly equal to $80^{\circ} \mathrm{C}$. Because the deformationresistant ability of the bloom corner is far higher than that of other positions due to it having the lowest temperature on the bloom inner surface, the contact length between the bloom corner and rolls is the smallest on the inner surface. Therefore, the temperature dips of point $A$ were far smaller than

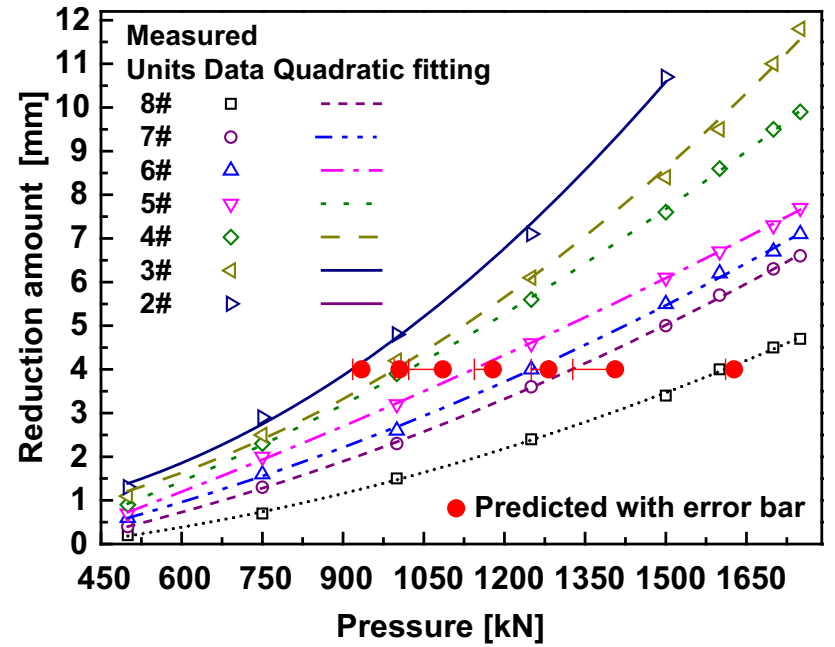

Fig. 4. Measured and predicted relationship between the reduction amount and pressure of each unit.

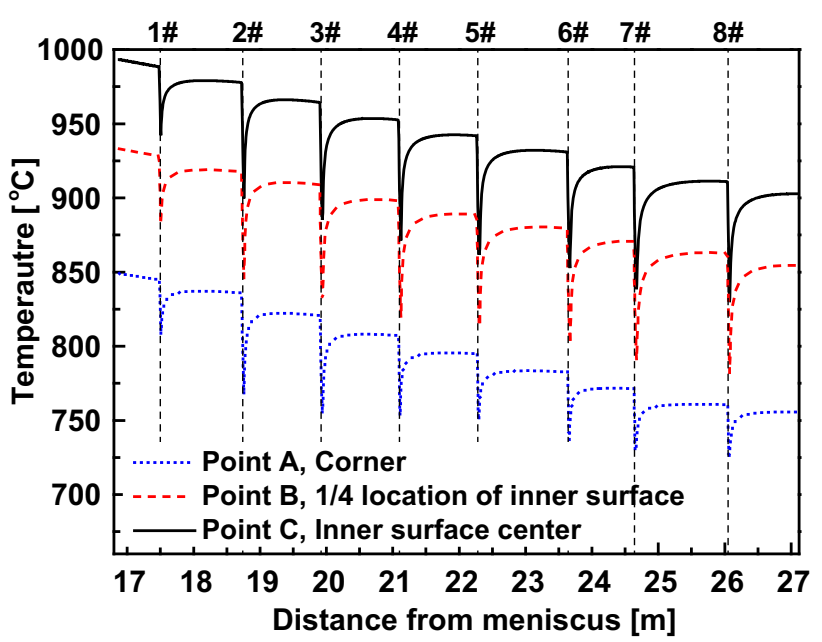

Fig. 5. The temperature distribution of typical points during the HR process.

those of points $B$ and $C$, and they decreased gradually along the casting direction due to the decreasing contact length.

The solidus isolines with and without HR in the middle of the longitudinal section of the strand are compared in Fig. 6. The solidus isoline was compressed toward the outer surface due to the HR, and the amount of compression on the upper half of the bloom was larger than that on the lower half of the bloom because the HR was implemented by the upper roll of the units. The solidification end after HR deviated $12.15 \mathrm{~mm}$ from the original bloom center toward the bottom surface of the bloom.

In the bloom HR process, the contact area between the bloom and rolls was evidently prolonged, and the heat transfer distance from the liquid core to the bloom surface was continuously reduced. Therefore, 


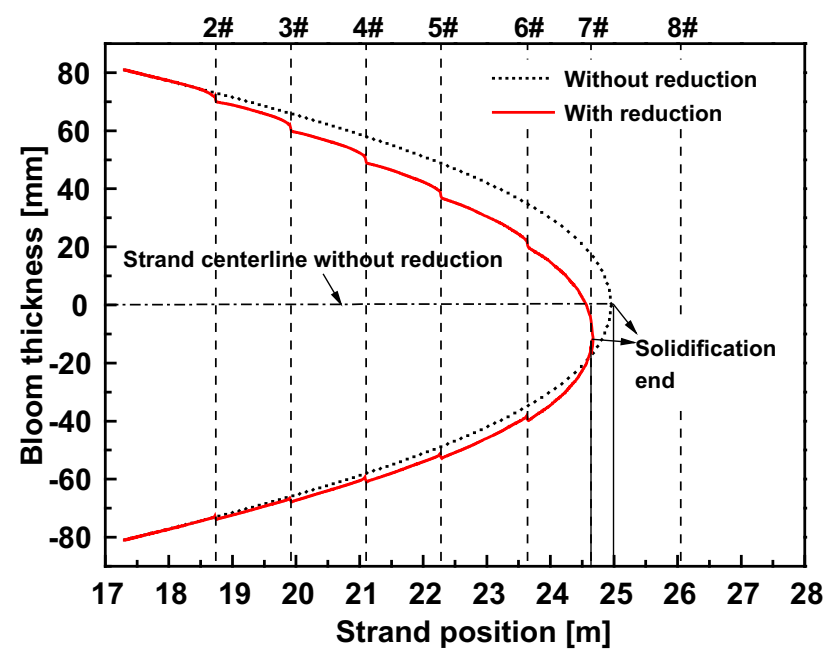

Fig. 6. Solidus isolines in the bloom thickness direction with and without HR.

the heat extraction during the HR process was enhanced, and the solidification end moved toward the meniscus by $0.295 \mathrm{~m}$ as shown in Fig. 6 .

\section{Distribution of the Reduction Amount}

Figure 7 shows the distribution of the HR amount of the typical points. As shown in Fig. 7a, there are obvious surface rebounds between each of the two neighboring rolls, which are mainly caused by the alternate HR process of "compression-relaxationcompression", and the corner rebound is lower than other points due to its higher deformation-resistant ability. As for points $B$ and $C$, the bulging occurred just before the roll-bloom contact area. The broadening deformation of point $B$ is blocked by the solidified bloom narrow side, and the "accumulation effect" obviously enhanced the bulging. The broadening deformation in the bloom corner could be released freely in the width direction, and no bulging occurs at point $A$.

In the direction of the bloom thickness, as shown in Fig. 7b, the HR amount transferred from the bloom surface to the center gradually, and in this case, the transfer efficiencies of the HR amount in the bloom quarter and center are approximately $85 \%$ and $50 \%$, respectively. Between two neighboring rolls, the rebound in the bloom inside is lower than that at the surface due to its longer HR transfer distance, and the bulging just before the roll-bloom contact areas is almost invisible at points $D$ and $E$ due to the same reason.

\section{Distribution of the Equivalent Strain}

The equivalent strains of typical points are shown in Fig. 8, and they all increased stepwise because the reduction in the deformation of the bloom occurred only under the units.

Figure 8a compares the equivalent strains of the points on the bloom inner surface. Because the corner temperature is lowest on the bloom cross- section, the deformation-resistant ability of point $A$ is the highest, and, correspondingly, the equivalent strain of point $A$ is the lowest. Because the temperature decreases along the casting direction, the incremental equivalent strain of point $A$ under the sequential units decreases gradually. The temperatures of the width $1 / 4$ location and center location on the inner surface are almost the same, but the equivalent strain of point $B$ is much higher than that of point $C$ due to its larger broadening deformation in addition to the reduction deformation. The equivalent strains of points $B$ and $C$ decreased before the sharp increases due to the obvious bulging just before the roll-bloom contact areas as shown in Fig. 7a.

As shown in Fig. 8b, the equivalent strain of the inner surface is the largest because the HR acts on the inner surface directly. Because the deformationresistant ability at the bloom center is the lowest, the equivalent strain of point $E$ is higher than that of point $D$ (the bloom quarter). It could be inferred that the lowest equivalent strain in the HR process is not located at the bloom center, and the HR could be transmitted to the bloom center successfully.

\section{Results in Plant Application}

Based on the simulation results of the FE model and the reduction amount calculation method, ${ }^{1}$ the preliminary reduction parameters of the two-stage sequential HR method were designed with a casting speed of $0.45 \mathrm{~m} / \mathrm{min}$. Before the solidification end, the total reduction amount was approximately $13.5 \mathrm{~mm}$, which was executed by the third to the sixth units. At and after the solidification end, the HR was executed by the seventh to the ninth units, and the total reduction amount was $15.5 \mathrm{~mm}$ according to the maximum reduction ability of the caster. The total reduction amount of the whole strand is $29 \mathrm{~mm}$, and the reduction ratio is $7.63 \%$ for a $380-\mathrm{mm}$ thickness GCr15 bloom.

The designed HR parameters have been applied to the above-mentioned bloom continuous casting machine. The blooms with and without HR were sampled at the same time but from different casting strands, and the macrographs of the blooms and rolled bars $(\phi=110 \mathrm{~mm})$ transverse section with and without HR are compared in Fig. 9. It can be clearly seen that the serious porosity and shrinkage cavities in the bloom center were evidently eliminated after the HR was applied, and, correspondingly, the homogeneity and compactness of the rolled bar were improved.

\section{CONCLUSION}

A two-stage sequential HR method has been proposed to simultaneously improve the homogeneity and compactness of the continuous casting bloom, and a 3-D thermal-mechanical coupled FE model was built to investigate the effect of the twostage sequential HR on the thermal and mechanical 

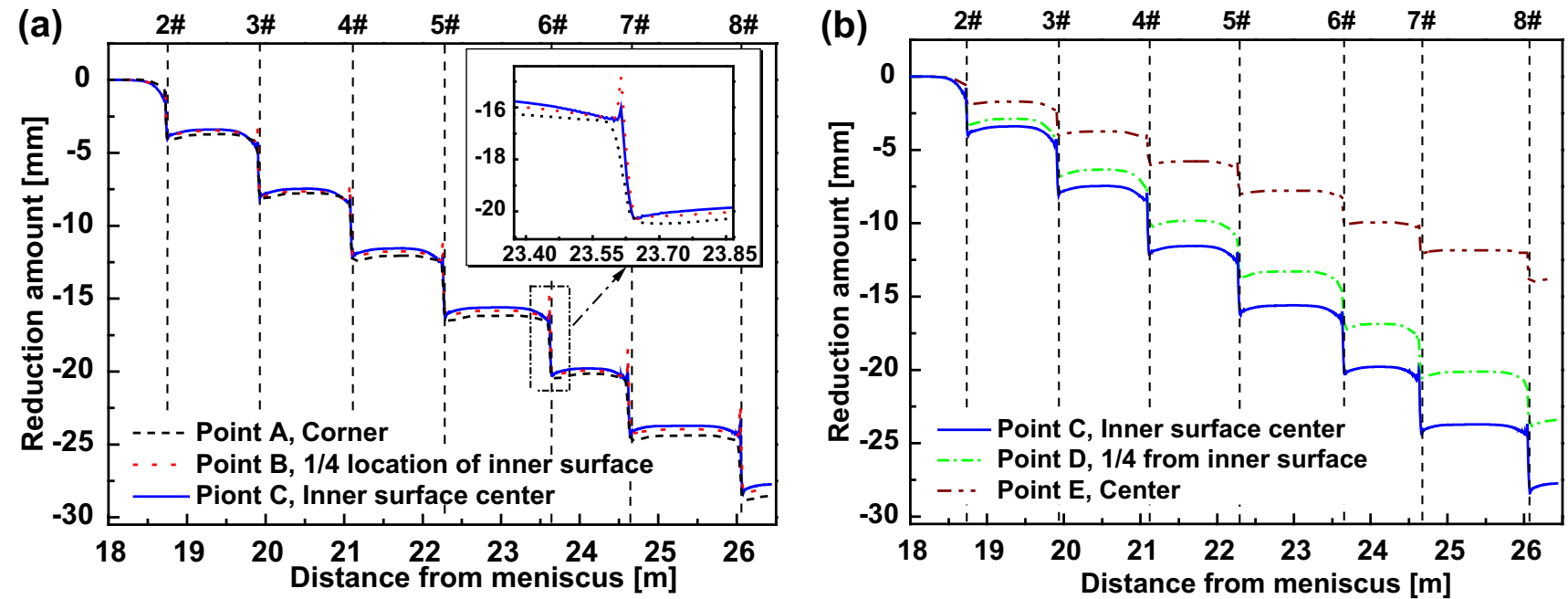

Fig. 7. Evolution of the $\mathrm{HR}$ amount at typical points: (a) points $A, B$ and $C$; (b) points $C, D$ and $E$.
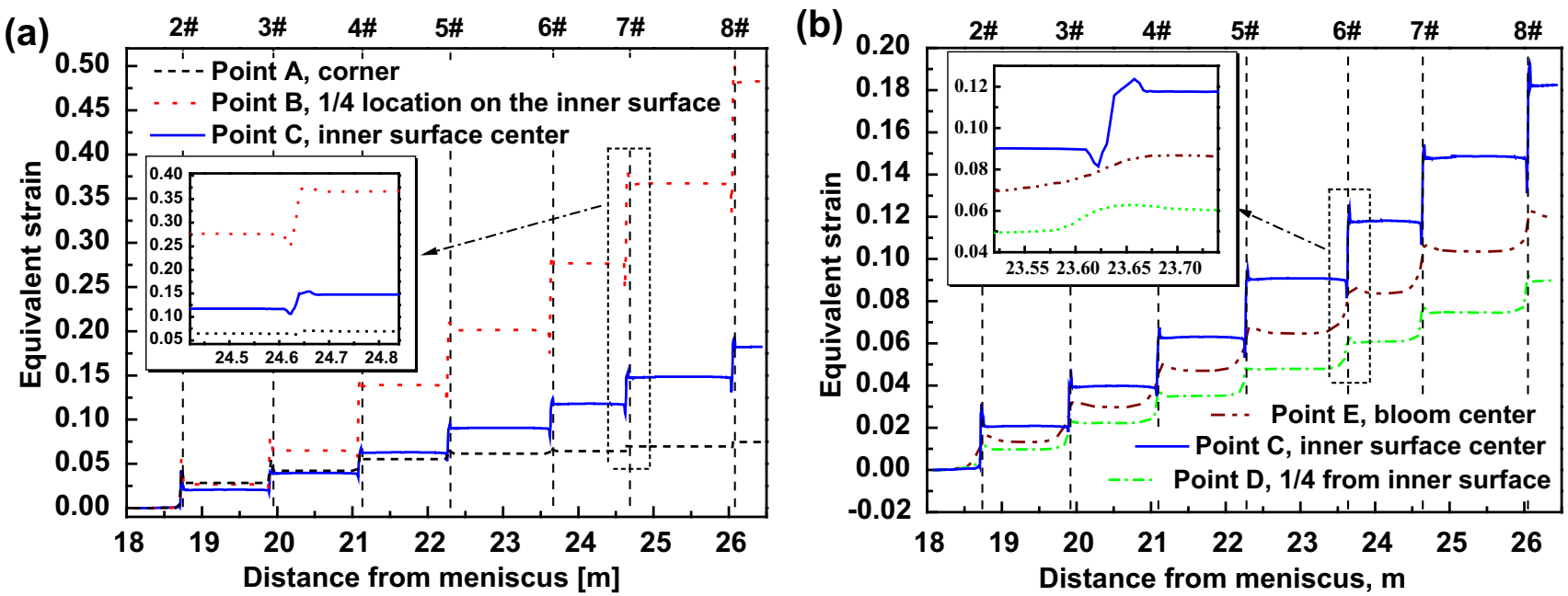

Fig. 8. Evolution of the equivalent strain at typical points: (a) points $A, B$ and $C$; (b) points $C, D$ and $E$.

behaviors of the GCr15 bloom. An Anand constitutive model was chosen to describe the relationship between the inelastic strain rate, temperature and flow stress of the GCr15 bloom, and the model parameters were derived from the experimental results. In order to verify the accuracy of the model with respect to the thermal behavior, the predicted surface temperature and shell thickness were verified by the thermal infrared camera and nail shooting results with relative errors $<0.91 \%$ and $2.67 \%$, respectively. The real measured relationship between the pressure and reduction amount of each unit were applied to verify the accuracy of the mechanical model, and the mean relative error is $2.95 \%$.

The typical casting case was simulated and analyzed, in which the reduction amounts of the second to eighth units were all assumed to be $4 \mathrm{~mm}$ with a casting speed of $0.45 \mathrm{~m} / \mathrm{min}$. In the $\mathrm{GCr} 15$ bloom HR process, the heat extraction of the rollbloom contact was enhanced, and the solidification end of the strand moves toward the meniscus by $0.295 \mathrm{~m}$. The surface rebound between two neighboring rolls was caused by the alternate reduction process of "compression-relaxation-compression". The "accumulation effect" caused by the blocked broadening deformation enhanced the bugling of the bloom inner surface just before the roll-bloom contact area, and the bloom corner has no bulging due to the freely released broadening deformation. In this case, the transfer efficiencies of the reduction amounts in the bloom quarter and center are approximately $85 \%$ and $50 \%$, respectively, and the equivalent strain of the bloom center is higher than that of the quarter due to its lower deformationresistant ability. 

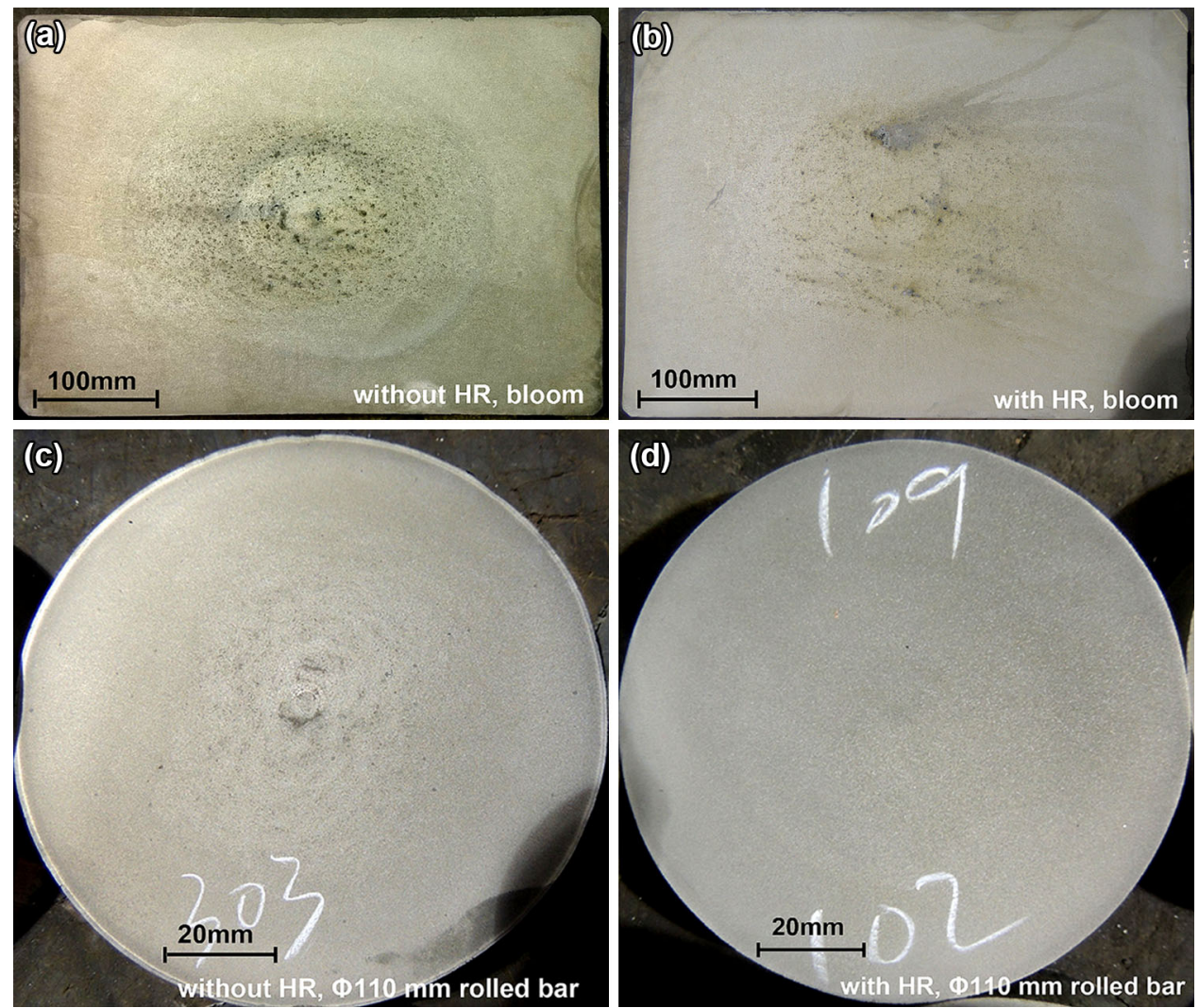

Fig. 9. Macrographs of the transverse sections of blooms and rolled bars: without HR $(a, c)$; and with HR (b, d).

The explorative industrial application showed that the bloom center quality and compactness of the rolled bars were improved significantly with the new HR method. Furthermore, through combining it with more industrial experiments, the model could be applied to investigate the two-stage sequential HR process systematically, such as optimization of the reduction amount, calculation of the reduction efficiency, calculation of the maximum reduction amount to avoid internal cracks, etc.

\section{ACKNOWLEDGEMENTS}

The present work is financially supported by the National Natural Science Foundation of China No. 51,474,058 and U1560208, the Program for Liaoning Excellent Talents in University (LJQ2015036) and Fundamental Research Funds for the Central Universities of China (N150205002). Special thanks are due to our cooperating company for industrial trials and applilcattion.

\section{OPEN ACCESS}

This article is distributed under the terms of the Creative Commons Attribution 4.0 International License (http://creativecommons.org/licenses/by/4.0/), which permits unrestricted use, distribution, and reproduction in any medium, provided you give appropriate credit to the original author(s) and the source, provide a link to the Creative Commons license, and indicate if changes were made.

\section{REFERENCES}

1. C. Ji, S. Luo, and M.Y. Zhu, ISIJ Int. 54, 504 (2014).

2. C. Ji, S. Luo, M.Y. Zhu, and Y. Sahai, ISIJ Int. 54, 103 (2014).

3. S. Nabeshima, H. Nakato, T. Fujii, T. Fujimura, K. Kushida, and H. Mizota, ISIJ Int. 35, 673 (1995).

4. S. Kojima, H. Mizota, and K. Kushida, Kaw. Steel Giho 26, 1 (1994).

5. Y. Matsuoka, Y. Miura, H. Higashi, and S. Kittaka, The METEC and 2nd ESTAD. Session 19, 1 (2015).

6. S. Hiraki, A. Yamanaka, Y. Shirari, Y.Sato, and S. Kumakura, Materia 48, 20 (2009).

7. M. Kawamoto, J. Iron Steel Res. Int. 18, 28 (2011).

8. G.S. Li, W. Yu, and Q.W. Cai, J. Mater. Process. Technol. 227, 41 (2016).

9. C.H. Yim, Y.M. Won, J.K. Park and H. Kwon, U.S. Patent, US8245760B2 (2012).

10. X.K. Zhao, J.M. Zhang, S.W. Lei, and Y.N. Wang, Steel Res. Int. 85, 645 (2014).

11. X.K. Zhao, J.M. Zhang, S.W. Lei, and Y.N. Wang, Steel Res. Int. 85, 811 (2014).

12. K. Miyazawa and K. Schwerdtfeger, Arch Eisenhuttenwes 52,415 (1981).

13. T. Kajitani, J.M. Drezet, and M. Rappaz, Metall. Mater. Trans. A 32A, 1479 (2001).

14. M.H. Wu, J. Domitner, and A. Ludwig, Metall. Mater. Trans. A 43A, 945 (2012). 
15. T. Nozaki, J. Matsuno, K. Murata, H. Ooi, and M. Kodama, Trans. Iron Steel Inst. Jpn. 18, 330 (1978).

16. J.X. Fu, J.S. Li, and H. Zhang, Acta Metall. Sin. 46, 91 (2010).

17. C.S. Li and B.G. Thomas, Metall. Mater. Trans. B 35B, 1151 (2004).

18. G. Xia and A. Schiefermuller, Steel Res. Int. 81, 652 (2010).

19. L. Anand, J. Eng. Mater. Technol. 104, 12 (1982).

20. S.B. Brown, K.H. Kim, and L. Anand, Int. J. Plast. 5 , 95 (1989).

21. F. Yin, L. Hua, H. Mao, and X. Han, Mater. Des. 43, 393 (2013).

22. H. Mizukami, K. Murakami, and Y. Miyashita, Tetsu to Hagane 63, S562 (1977).
23. M. Uehara (M.Sci Thesis, University of British, Columbia, 1983), p. 17.

24. M. Bellet and A. Heinrich, ISIJ Int. 44, 1686 (2004).

25. V.D. Fachinotti, S. Le Corre, N. Triolet, M. Bobadilla, and M. Bellet, Int. J. Numer. Meth. Eng. 67, 1341 (2006).

26. Q.Y. Lin and M.Y. Zhu, Jinshu Xuebao 43, 1301 (2007).

27. J.X. Song, Z.Z. Cai, F.Y. Piao, and M.Y. Zhu, J. Iron. Steel Res. Int. 21, 1 (2014).

28. T. Kawawa, H. Sato, S. Miyahara, T. Koyano, and H. Nemoto, Tetsu-to-Hagané 60, 206 (1974). 